\title{
A REVIEW OF EXPERIMENTAL WORK IN SYPHILIS AND ITS POSSIBLE BEARING ON MAN
}

\section{Discussion I. MaY 3Ist, I929}

The PREsident said he was sure all present had listened with very great interest to the admirable paper which Colonel Harrison had just presented. No one who had attempted to analyse and condense a large amount of scientific material on such an abstruse subject as this could fail to realise the enormous difficulties which Colonel Harrison had so successfully dealt with, and it would be the wish of those who had heard the paper to accord to the reader their hearty thanks.

Perhaps the discussion would be continued on another occasion.

The thanks were carried by acclamation.

Dr. DAvid LeEs wished to congratulate Colonel Harrison on the excellence of his review. It was very difficult in such a comprehensive review to follow every word closely. The closing words which Colonel Harrison used, to the effect that the patient's constitution should be considered when treatment failed, were of great importance. "Constitution" was a difficult thing to define, and he would like to have heard from Colonel Harrison some reason why one patient responded well to treatment while others did not. For example, a patient with an extensive rupial rash might clear up both clinically and serologically, while a second patient with less marked clinical signs of disease failed to react to treatment. What were the methods which we might utilise in our work to reinforce the resistance of those patients who did not respond to treatment?

Colonel Harrison had referred to the value of endocrine therapy, which had been advocated by Pearce and Brown, as a means of influencing the patient's constitution. From practical experience the speaker was doubtful of its value, as he had practised both monoglandular and v.D. 


\section{BRITISH JOURNAL OF VENEREAL DISEASES}

polyglandular therapy, but could not conscientiously say that his patients had obtained any benefit from it. Neither had he been able to obtain any assistance or advice from authorities on endocrinology. There was no doubt whatever that the successful treatment of syphilis depended on something more than the injection of drugs.

Another point mentioned was the effect of artificial light on the production of immunity and the effect of heat. Pearce and Brown had suggested that hot baths killed the Spirochata pallida in situ. If so, the position was different from that which had been suggested as an explanation for the curative value of malarial therapy in G.P.I. In the latter the main evidence so far showed that the improvement after the pyrexia is due to the re-establishment of lymph drainage in the nerve sheaths.

Colonel Harrison, when speaking of the life-cycle of the spirochæte, had stated that it was difficult to prove this by means of the microscope, and certainly affinity for silver staining was not sufficiently strong evidence to prove that there was a life-cycle.

In dealing with experimental work carried out in animals it was important to remember that the results obtained are not similar in all animals, and that these results do not always hold in the human being. For the last eighteen months, in observing the effect of chemotherapeutic remedies of various types administered to animals suffering from rat-bite fever, it was found that some of the drugs which were very efficient in curing lesions in the human being were not nearly so effective in animal subjects. Similarly, remedies which were considered less effective in the human being proved more effective in the case of animals. It was advisable, therefore, to exercise caution in reading the results of animal experimentation. As Colonel Harrison had stated, the tissues of the mouse showed a definite tolerance for syphilis, and in some cases did not show any lesions for a long time. Just as with the test tube in bacteriology, so with animal experimentation, one could not always argue that the process was similar in the human being.

In listening to Colonel Harrison's extensive review, it was very striking that practically all the work had been carried out elsewhere than in Britain. Our syphilologists apparently had not time to carry out research work nor time to confirm the work done elsewhere. 


\section{EXPERIMENTAL WORK IN SYPHILIS}

Something should be done to make it possible for workers in this field of medicine to do part-time research so as to obtain the maximum information from the immense amount of material with which we are dealing. Clinicians, if they had time, were in a position to assist greatly in research, and especially in chemo-therapeutic research.

This extensive review must of necessity make all who had heard it think hard and also take a serious view of this disease. In one part of the paper arguments were advanced in favour of not treating a case of syphilis before the sixtieth day. Even if immunity were more readily established in animals so handled, one would hesitate to recommend such delay in human syphilis in view of the well-known difficulty of obtaining a cure in cases where treatment was delayed.

He wished to congratulate Colonel Harrison on accumulating in the scope of this paper an immense amount of information, from which he personally had gained much information.

Dr. H. M. Hanschell also thanked Colonel Harrison for his paper, which he was looking forward to seeing in print. Although he had seen some of the papers referred to by the reader, he would be very glad of this critical review of all the work. They were all much indebted to Colonel Harrison for his labour.

He had been interested in the reference made to llama infections. Eight years ago he (the speaker) had a patient from the Andes who insisted that he had been infected with syphilis by a llama bite on the arm; certainly on the upper arm there were three gumma-like lesions, closely opposed in semicircular fashion. It was easy to imagine (while ignorant of the llama's dentition) that they were made by a llama's teeth. However, the man was such a one in appearance and conduct that it was easy also to imagine that he had likely enough infected the llama, instead of the other way about. Anyhow, he had an old sore on the penis. Later he, Dr. Hanschell, read some of the work of Brazilians who had inoculated the llama with syphilis. From this it appeared that the llama was readily susceptible to the disease. It had long been the belief in Peru that the llama carried the disease, and that men who looked after the animals acquired it from them. He had seen cited ancient rules made by the old-time Spanish authorities in Peru, under ecclesi- 


\section{BRITISH JOURNAL OF VENEREAL DISEASES}

astical prompting, whose object was to prevent syphilis infection of the drivers from the llama.

Colonel Harrison had said nothing to-night about the drug-fast spirochæte, nor about the even more hypothetical resistant granules. He (the speaker) wondered if belief in these had now weakened ; their actual existence had never been other than supposititious.

With regard to the relationship of the patient's constitution to the effects of treatment, he, like all his hearers, had been much struck by the difference in patients in this respect. He had found that some of the patients who did not respond well at first did so after they had been given cod liver oil, plus the same anti-syphilis treatment as before. He was even inclined to think that cod liver oil might be more important than iodide of potassium. That day he had read in the British Medical Journal Mellanby's paper on the great value of vitamin A in treatment of streptococcal septicæmia. Cod liver oil was rich in vitamins. He (the speaker) had sometimes found in cases resistant to treatment that inducing the man to restrain a too alcoholic habit resulted in better response to the same anti-syphilis treatment as before.

A man might be infected with syphilis and not show a chancre. Colonel Harrison said he had three examples in which it seemed to be the result of using a local antiseptic, i.e., suppression of primary chancre. He (the speaker) had notes of two cases in which the youths confessed to primary exposure to the disease out in the East, and a day or two after that exposure receiving an injection of arsenobenzol. After returning to England on leave, two months and three months later respectively, they sought examination. He had found in them no clinical sign of syphilis, but their blood gave a strongly Wassermann positive reaction. Both those men very definitely denied that they had ever had a chancre. He had had a case in a woman whom he had treated for primary chancre and florid secondaries seven years ago, and for five years he had watched her. She remained Wassermann negative, and in the meantime had given birth to two children, both of them healthy and with Wassermann negative blood. Her husband had continually given a Wassermann negative blood. She had now returned with a strongly positive Wassermann blood. The husband died. She confessed that about a year ago she 


\section{EXPERIMENTAL WORK IN SYPHILIS}

had had sexual relations with several men other than her husband. On these occasions she had used lysol douches. She had not noticed either a primary lesion or secondary manifestations - in fact, nothing like what had happened seven years ago. He wondered if this were a true second infection, with suppression of primary chancre by the antiseptic douches and later suppression of noticeable secondary rash as well.

One saw striking differences in the reactions to drugs in man as compared with reactions in the lower animals, both infested with the same parasite. Possibly difference in diet might account for some of it. The kitten, for instance, was susceptible to infection with amœbic dysentery, on which emetine had little or no effect in the kitten. The rabbit was a rodent and vegetarian; man was not the first of these and seldom the second. The therapy of rabbit syphilis could therefore not be safely applied too strictly to human syphilis.

His clinical experience so far showed that insufficient treatment in the primary stage of syphilis, or one or two arsenobenzol injections after exposure to infection on the off-chance of killing a possible infection, led, as a rule, to great resistance to subsequent treatment. For the individual patient it was better not to treat at all in the early stages than to treat inadequately. Though, perhaps, from the point of view of the public health, it was justifiable to treat enough to abolish or sterilise a chancre even though one could not continue treatment beyond that stage. Suppression of primary and secondary stages might serve to prevent infection being passed on to others.

Dr. H. C. SEMon desired to add to those of others his congratulations to Colonel Harrison on his paper. The subject was so enormous, however, that, especially at such a late hour, one could not dwell on more than one or two points.

He had been feeling critical about the experiments on super-infection in animals which had been treated, and he asked whether there might not be a fallacy, which would vitiate conclusions, in that those animals had had treatment, and thereby salvarsan and bismuth depôts were established in them, which depôts might, at a later stage, act in protecting the animals against further infection. That was a point which he thought was worthy of comment. 


\section{BRITISH JOURNAL OF VENEREAL DISEASES}

Colonel Harrison's remark as to the tendency of chancres to develop on previously damaged tissues reminded the speaker that a similar happening might be observed in the case of psoriasis. In the latter disease it was very common to see lesions occurring on tattoo marks.

When he received a synopsis of Colonel Harrison's paper he was reminded of a most interesting case which he would like Dr. Lees to look at, as it answered that gentleman's question as to what constituted the unknown factor in cases in which patients failed to react to treatment of various grades. The case was published in the Dermatologische Wochenschrift (I928) by Rosener, and concerned a chauffeur, who was very thoroughly treated for a primary chancre and secondary manifestations with 4.5 grammes of N.A.B. and mercury injections. Fourteen days after stopping that treatment he developed secondaries in various parts of the body, and his Wassermann was negative. Further treatment had no effect in clearing up the manifestations, but the Wassermann continued to be negative. The patient was injected with luetin, and after one or two injections his lesions commenced to clear, the Wassermann remaining positive.

\section{Discussion II. JULy I2th, I929}

The President reminded members that at the last meeting Colonel Harrison gave a very valuable contribution, full of information, and one for which they felt much indebted to him. He also went into several abstruse matters related to immunity and infection. Many of the lessons drawn from the experimental work were somewhat disconcerting to those concerned with treating the disease, because they upset the preconceived ideas on the subject. Immunity was a very complex subject, and one with which the generality of medical men were not very familiar. That applied to both tuberculosis and syphilis. At the last meeting Dr. Lees expressed what many would agree with, that Great Britain was behind in this experimental research ; he hoped that before long such a reproach would be removed. In that respect the United States furnished a very fine example, as much valuable research work on the subject was being done there. By a stroke of good fortune to-night's meeting 


\section{EXPERIMENTAL WORK IN SYPHILIS}

coincided with the visit to this country of Dr. Louise Pearce, of the Rockefeller Institute, and it was very gratifying to all the members that she had been able to accept the Society's invitation to come and speak that night. The Society welcomed her, not only because of her distinguished work on venereal disease, but also because she was one of our cousins from across the sea.

Dr. Louise PEARCE wished, before commencing to give her observations, to express her pleasure at being present. It was totally unexpected. She arrived in Liverpool ten days ago, and before she left the boat she received a telegram from Colonel Harrison asking her to be present. On arrival in London she received a copy of his paper, and read it at once with much pleasure. She congratulated the members on having enjoyed the privilege of hearing such an able review of a complex subject.

In speaking to Colonel Harrison on the previous day as to what she should say, it was concluded that it would be of some interest to members if she were to outline briefly some of the experiments of herself and colleagues at the Rockefeller Institute, i.e., experiments carried out by Dr. Wade Brown and herself.

As they worked entirely with the rabbit, she would first speak of syphilis as found in that animal. It was as characteristic in the rabbit as was the disease in the human. Strains of virus which had become well adapted to rabbits, having been passed through them many times, and capable of producing disease manifestations, were largely used. The disease was chronic, non-lethal and self-limited, in that the manifestations eventually disappeared. But the rabbit remained infected as long as it lived, and one could usually recover the organisms from the lymph nodes. Two or three weeks after intratesticular inoculation one saw the first clinical manifestations of the disease. In the third week there was a welldeveloped primary orchitis, and after two or three more weeks that lesion had regressed and was followed by the first so-called latent period. After a variable period of time-approximately seven weeks after inoculation-if one had inoculated one testicle, there occurred a metastatic orchitis, and shortly afterwards secondary lesions in the bones, followed by lesions of the skin and mucous membranes. Later still the eyes were implicated. At the 


\section{BRITISH JOURNAL OF VENEREAL DISEASES}

end of three to four months the disease manifestations were usually healed, except perhaps residual lesions of the testicles, tunics, and epididymes. A rabbit in which all lesions were healed could be demonstrated to be a carrier by inoculation of certain tissues into other animals, and for this purpose the popliteal lymph nodes are used. The order of lesions mentioned-bones, skin and mucous membrane, eyes-was not entirely constant; indeed, one of the prominent features of the disease was its variability. This feature is also shown by the character of the infection developing in individual animals of a group. In five rabbits inoculated at the same time and in the same manner there was apt to be severe syphilis in one, a mild disease in one, and intermediate grades of disease severity in three animals respectively. It was essential in work of this kind to employ a large number of animals.

Their criteria of severity were numerous, and included shortness of incubation period, the degree and persistence of the primary lesion, the number and location of generalised lesions, their destructiveness, and their persistence. The bone lesions were usually of the extremities and involved the epiphyses, and the skin lesions were also of the extremities and face. The eye lesions were keratitis, iritis, etc. Close clinical observation was necessary, and rounds were made every morning, just as in a human hospital ward. As far as the spirochæte was concerned, it was necessary to work with virulent strains capable of inducing gross lesions when clinical manifestations were desired. The dose, also, must be adequate, and the route of inoculation was of great importance. For most experiments the intratesticular or scrotal route was used. The results of intravenous inoculation, in which no primary lesions were supposed to have occurred, were open to another interpretation; in regard to many of these experiments one might say that after such a method of inoculation there were multiple primary lesions.

In all of this work the part played by the host versus the spirochæte was striking, and it appeared at present that the host factor was the more important. In regard to the host factor, one considered such things as breed, sex, age, and general condition. At one time it was thought that the ordinary albino rabbit gave the most satisfactory results, in that the disease seemed to be 


\section{EXPERIMENTAL WORK IN SYPHILIS}

most severe in this breed. But after the subject had been studied more closely, it was concluded that the ordinary grey-brown rabbit was best. In the New Zealand red rabbit, for example, the disease tended to be mild.

The factor of environment was important. It was curious to observe the effect of caging, of a sedentary life and of age. The animals were brought to the laboratory in large crates. All of them were then separately caged, a desirable procedure, and were fed on a standard diet. If animals were inoculated within two or three days of being brought in, the usual result was a more severe disease than if the animals were first kept for two or three weeks. The disease in older rabbits was much less severe than in young adult rabbits.

The disease was more severe in the spring and autumn than in the winter and summer months. There seemed to be a relationship between the general severity of the disease and the total hours of sunshine. In one experiment to test the effect of light, three separate animal rooms were used : one had the usual lighting with leadglass windows; the second was constantly and continuously illuminated; the third was kept in complete darkness. The temperature and humidity conditions were controlled by connections with a common ventilating system. The same number of rabbits were placed in each of the rooms, as, for example, ten in one experiment. They were kept in these conditions a certain time before inoculation, as well as during the four months of the experiment. In summarising the results, she preferred to speak of resistance to the disease, emphasising the host factor rather than the lesions or disease manifestations themselves. It was found that the resistance to the disease, or the efficacy of the reaction, increased with the amount of light and the constancy of exposure to it. This experiment was repeated many times. In the dark room one also observed deterioration in the animals. During the first six months, however, they remained in excellent shape and gained weight.

Colonel Harrison referred in his paper to some of the speaker's observations on the endocrine glands and the changes noted in them in syphilitic animals. These changes were particularly of the thyroid, thymus, and parathyroid. They were very characteristic, and led to 


\section{BRITISH JOURNAL OF VENEREAL DISEASES}

the experiments which she would next describe. Complete and partial thyroidectomy and thymectomy were performed and the rabbits subsequently inoculated. In the completely thyroidectomised rabbits she had seldom seen such severe syphilis. In other experiments rabbits. were given varying amounts of potassium iodide. As a general conclusion to all of this work, it seemed that resistance to the disease was subject to the same influences as were concerned in the regulation of growth and the maintenance of general metabolic activity.

In another set of experiments the subject of double or concomitant infections was considered. It was found that an animal which had been sent to the laboratory from Europe, supposed to be infected with a certain strain of pallidum, also carried a vaccinia virus. The syphilis resulting from inoculations from this animal was unusually mild, and she then began a series of experiments, working with pure strains of pallidum and vaccinia virus to determine the effect of the one infection on the other. It was observed that if one simultaneously inoculated intracutaneously with vaccinia virus and intratesticularly with pallidum the resulting syphilis was extremely severe, while the reaction to the vaccinia virus was also very severe, recalling hæmorrhagic small-pox. If, on the other hand, the pallidum inoculations were made in vaccinia-immune rabbits, a very mild syphilis developed. And the injection of a mixture of vaccinia and pallidum emulsions into the same testicle induced very mild syphilis. In the last experiments there had been, in consequence of the vaccinia inoculation, a considerable damage to the testicular tissue and probably the destruction of a certain proportion of the pallidum organisms, as well as the induction of a vaccinal immunity. These events occurred well before the usual time of the development of the primary syphilitic lesion as determined clinically. All the animals, however, eventually developed syphilitic manifestations. The influence of one infection on the other was one which, especially in children, physicians had recognised for a long time, but she did not think it had been taken sufficiently into account from an experimental standpoint.

She and her colleagues were now working on the blood with regard to the calcium and phosphate and the cholesterin and lecithin content, as well as the cytological 


\section{EXPERIMENTAL WORK IN SYPHILIS}

picture. For example, there was found to be a tremendous: increase in the mononuclear cells of the circulating blood during active phase of the disease. The same changes were also seen in other infections, and in a malignant tumour in rabbits, so that the condition was not specific. These studies were carried out with the supravital neutral red technic.

Dr. Pearce added that due caution should be observed in applying the results of animal experimentation to the problem of the human disease. It was true that the condition as observed in the experimental animal presented many points of similarity to the disease in man, but there were also important differences. She emphasised, too, that in order to be of value it was essential that the evidence should come from those who were: thoroughly familiar with the experimental disease, which involved, among other features, an adequate animal material. One read of experiments in a paper of several pages, and on sifting it down it was found that a few animals, perhaps seven or eight, were referred to and apparently formed the basis of the conclusions drawn. Those who had worked at the subject for even a short time realised that such a material was quite inadequate and might easily be misleading. The experimental disease, however, did afford a means of testing ideas under controlled conditions, but the application of the results. obtained should be made with due regard to clinical observation and experience.

The PRESIDENT said he was sure that those present would wish him to express on their behalf-as he certainly did on his own - their great indebtedness to Dr. Louise Pearce for the talk she had given. Those who had had experience in animal research work did not need to be told what an enormous amount of labour was involved, and how long and patiently it was necessary to work in order to establish an apparently small truth. He had the greatest admiration for the work being carried out by Dr. Pearce and her collaborator; it meant prolonged and most attentive concentration on details.

Mr. LEES wished to associate himself with the President in congratulating Dr. Louise Pearce on the very clear and interesting exposition which she had given of some of the research work she had been carrying out at the Rockefeller Institute. The Society were fortunate in having. 


\section{BRITISH JOURNAL OF VENEREAL DISEASES}

this information first hand from one of the ablest research workers in any country. Her last sentence was of very great importance. In it she cautioned every one against applying the results of experimentation in animals too closely to the human being. Just as this caution was required in reading the results of animal research, so also as clinicians great caution was required of them in reading too much from the results of treatment in one or two cases. There was no more fatal error in studying syphilis than to generalise on a limited experience, and there was no pathological condition in which there was greater variation in the clinical picture and in the reaction to treatment.

With regard to Colonel Harrison's review of experimental work on syphilis, he wished to voice the feelings of most of them in stating the debt of gratitude which they as clinical workers owed to Colonel Harrison for enabling them, by a review such as this, to keep abreast of modern literature. The field he covered was so vast that it was impossible to digest the information he had given them even in the month which had elapsed since the previous meeting. The information given on " anergie," either natural, partial or artificial, was striking; only last week the speaker had come across a case in which the primary lesion appeared in eleven days in the husband, but took from nine to ten weeks to appear in his wife. The strain was homologous, but the "anergie" of the hosts was obviously different. Kolle and Evans' work on the effect of antiseptics as tending to produce a partial " anergie " was very valuable, and should make one careful of their use in the prophylaxis of acquired syphilis; personally, the speaker was of the opinion that the only true prophylactic of incubating syphilis was the injection of the arsenobenzol compounds. Of great interest also was Kolle and Prigge's work on bismuth. It appeared to discount the value of bismuth as a therapeutic agent in that it cleared up the surface lesions, but did not, unless given over long periods, eradicate the lymphatic infection. In spite of this work there were clinical cases in which arsenobenzol exhibited for long periods and mercury with it failed to clear up active syphilis. When bismuth was exhibited in some of these cases it appeared to act extremely well and to supply something which had been wanting in the other therapeutic methods. It 


\section{EXPERIMENTAL WORK IN SYPHILIS}

certainly had a place in the therapy of syphilis in conjunction with other drugs, but should not be used alone.

The work of Levaditi and Schoen on the life-cycle of the spirochæte, in which they claim to have shown all forms, from spirals to ultramicroscopic granules, might have a far-reaching effect. It was not so very long ago that the late Amand Routh spoke of spirillolysis during syphilis in pregnancy as a possible explanation of many of the problems of inherited syphilis. If this ultramicroscopic granule form of the spirochæte is more resistant to chemo-therapeutic remedies than the higher developed spiral form, it might explain many of the resistant cases which were met with, and further investigation along these lines might help us to clear up many of the problems of resistant syphilis.

In view of the results being obtained from malarial therapy in G.P.I., the work of Brown and Pearce, Schamberg, Chesney, and others on the effect of light and heat in treating experimental syphilis was interesting. The general evidence from their experiments was that a temperature of $106 \cdot 2^{\circ}$ to $110 \cdot 6^{\circ} \mathrm{F}$. was lethal to the Spirochata pallida. It was very difficult, however, to see how by external methods this temperature could be applied therapeutically to the treatment of cases of human syphilis to produce effective results. We were only gradually getting to know how pyrexial therapy in G.P.I. acted, and the most recent investigations on the Continent suggested that it did so through re-establishing the lymph drainage in the nervous system. Undoubtedly, in every case of human syphilis there were factors, such as the endocrine system, the general health of the patient, and the general metabolism, which influenced and made for successful treatment. On this account, each patient must be treated as an individual entity, and everything done to enhance the resistance of the patient and increase his " anergie."

Interesting and valuable as was this résumé of recent research, we must remember that the results could not be taken as an absolute guide to the treatment of human syphilis. This applied more particularly to work on "anergie," which suggested delay in commencing treatment of early syphilis.

Research should be encouraged in view of its possible bearing on the problems of infection in human syphilis, 


\section{BRITISH JOURNAL OF VENEREAL DISEASES}

but it was a mistake to infer or to assume that in syphilis, or any other infective process, the course of the infection in animals was exactly similar to that in man.

Dr. PEARCE, replying to questions, said that no lesions of vessels were found, except in those of the heart, and even in those only seldom. She thought many more lesions would be found if looked for at the beginning of the secondary period, because in the instances she found they had occurred at the time that there were numerous bone and skin lesions.

Her experiments, however, had been of a different nature, and so these findings were incidental. The lesions in the rabbit seemed to be peripheral rather than central. She interpreted lesions of the eye in rabbit as being of the same order as those of the central nervous system in man, in that they appeared late in the course of the disease-except under conditions of malignant syphilis, when they might appear in the eye at the same time as the bone and skin lesions. Their occurrence or non-occurrence was determined by what went before. If an animal had had severe secondary bone and skin lesions, eye lesions in it were rare-i.e., the immunity was such as to protect the eye from developing lesions. On the other hand, if there were very few bone or skin lesions, eye lesions were constant. It was much the same position as the central nervous system occupied in man. One must also take into consideration whether the nervous system was not protected by what had gone before. 